\title{
Effect of different gingival margin restorations of class II cavities on microleakage: an in-vitro study
}

\author{
Ahmed Ibrahim Mahrous ${ }^{1}$, Hani Abdulmoniem Eltiti ${ }^{2}$, Iffat Mirza Ahmed ${ }^{1}$, Ebaa Ibrahim Alagha ${ }^{1}$
}

${ }^{1}$ Al-Farabi College of Dentistry and Nursing, Jeddah, Saudi Arabia

${ }^{2}$ Maghrabi Dental Centers, Jeddah, Saudi Arabia

Type of article: Original

\begin{abstract}
Introduction: Microleakage is one of the important contributing factors in the failure of resin restorations. The aim of this study was to determine the effect of the location of the gingival margin (enamel, dentin, or cementum) on nanohybrid composite resin on the microleakage of Class II posterior restoration.

Methods: This was an in vitro study done at Al-Farabi College of Dentistry and Nursing in Jeddah (Saudi Arabia). Eighty-one previously extracted human molars were taken from clinics at Al-Farabi College and divided into three main groups (27 each) according to the location of the gingival margin. Group 1: the location of the gingival margin was in the enamel. Group 2: at the cemento-enamel junction. Group 3: in the cementum. Each main group was divided into three subgroups ( 9 each) according to storage time. Subgroup A: storage time was 24 hours. Subgroup B: storage time was one month. Subgroup C: storage time was three months. Class II cavity was prepared in one proximal surface for each molar following the general principles of cavity preparation. All samples were restored by nanohybridresin composite (TetricEvoCeram). The specimens were stored in distilled water at $37{ }^{\circ} \mathrm{C}$ and a humidity of $100 \%$ in an incubator for one day, one month, and three months, respectively, according to the subgroups. After sealing, the samples were stained with $2.5 \%$ methylene blue dye. Each sample was examined microscopically by a stereomicroscope using a computerized image analyzing system. Statistical analysis was done by two-way ANOVA test comparing dye penetration mean values $(\mu \mathrm{m})$.

Results: The value of dye penetration increased remarkably from enamel, Cemento-enamel junction [CEJ] to cementum, and this was statistically significant $(\mathrm{p}<0.001)$.

Conclusion: None of the materials tested was able to completely eliminate marginal microleakage at different gingival margins. The least dye penetration was detected at the enamel gingival margin followed by CEJ and then cementum. The least microleakage was observed at the gingival margin located in the enamel.

Keywords: class II restoration, gingival margins, microleakage, nanohybrid composite
\end{abstract}

\section{Introduction}

Esthetic appearance has become crucial in modern dentistry. Due to the increasing importance of esthetic appearance, studies in restorative dentistry are directed towards meeting the expectations of patients and physicians. Such studies have concentrated on improving tooth-colored restorative materials and techniques to replace the lost dental tissue (1). Dental composites have been used as restorative materials since the early 1960s. The demand for posterior resin composite restorations has increased dramatically in recent years because of their ability to match the tooth's color, absence of mercury, biocombitability, and bonding to the tooth's structure (2). However, like all dental materials, composites have their own limitations, such as the gap that forms due to contraction of the polymeric material during setting, leading to marginal discoloration and leakage (3). The literature has shown that major marginal microleakage occurs on the gingival surfaces located in the dentin or cementum. This is because these two structures do not show the same conditions for adhesion to resin composites, whereas enamel has better results. In addition, difficulty in accessing the proximal boxes of the preparations and the control of contamination are

\section{Corresponding author:}

Dr. Iffat Mirza Ahmed, Al-Farabi College of Dentistry and Nursing, Jeddah, Saudi Arabia.

Tel: +966535256122, Email: iffatfarabi@gmail.com

Received: September 06, 2015, Accepted: October 20, 2015, Published: November 2015

iThenticate screening: September 09, 2015, English editing: November 01, 2015, Quality control: November 06, 2015

(C) 2015 The Authors. This is an open access article under the terms of the Creative Commons Attribution-NonCommercialNoDerivs License, which permits use and distribution in any medium, provided the original work is properly cited, the use is non-commercial and no modifications or adaptations are made. 
complicating factors for the restorative technique. In addition, dentin bonding is more difficult because of the heterogeneous nature of the tissue, which requires the bonding system to accommodate simultaneously the properties of the hydroxyapatite, collagen, smear layer, dentinal tubules, and fluids (4). Different techniques have been used to increase the seal between the composite restoration and the gingival margin in class II restorations. Although it is not possible to totally eliminate the shrinkage of the polymeric material, paying attention to minute details, such as making a careful insertion and using an appropriate curing technique, can minimize the stresses resulting from this phenomenon (5).

\section{Material and Methods}

Eighty-one freshly extracted human first molars were selected for this study. The inclusion criteria were teeth with normal morphological features and with less or no carious destruction. Exclusion criteria were teeth with visible cracks, morphological defects, and deep carious lesions. The selected teeth were cleaned to remove both tissue and calculus deposits, and then they were scrubbed with a hard toothbrush under running water. Then, they were dried with oil-free compressed air. The teeth were examined under magnifying lens $(5 x)$ to detect any morphological abnormalities, such as cracks and erosion. Any defective tooth was discarded and replaced by another tooth. This study was approved by the Ethics Committee of Al-Farabi College. The teeth were divided into three main groups (27 each) according to the location of the gingival margin. Group 1: the location of the gingival margin was in the enamel. Group 2: the location of the gingival margin was at the cemento-enamel junction. Group 3: the location of the gingival margin was in the cementum. A class II cavity was prepared in one proximal surface for each molar following the general principles of cavity preparation. No bevels were made at any of the margins of the prepared cavities (6). The cavities were approximately $4 \mathrm{~mm}$ in width and $4 \mathrm{~mm}$ in depth, and the gingival margin was about $1.5 \mathrm{~mm}$ from the axial wall. The depth of the gingival floor was placed according to each group. All samples were restored by nanohybrid resin composite (TetricEvoCeram). Nanohybrid composite was placed incrementally. The cavity was etched with $37 \%$ phosphoric acid gel (N-Etch, Ivoclar-Vivadent) for 20 seconds, rinsed thoroughly for 30 seconds with water according to the manufacturer's instructions, and then dried for five seconds with an oil-free air syringe. Bonding agent (N-Bond Total Etch, Ivoclar-Vivadent) was applied to the cavities by a brush, and spreading was done by a gentle blow of oil-free air. This was followed by light curing for 20 seconds according to the manufacturer's instructions using a visible light-curing unit $(3 \mathrm{H}$, Fit-Light S., China). After placing celluloid matrix band (GoMat, Ivoclar-Viva Dent), nanohybrid resin composite (TetricEvoCeram) was placed in increments by a plastic instrument and then light cured for 20 seconds according to the manufacturer's instructions. After restoration, the samples were polished by a finishing bur and rubber flame using a low-speed handpiece (Figure 1).

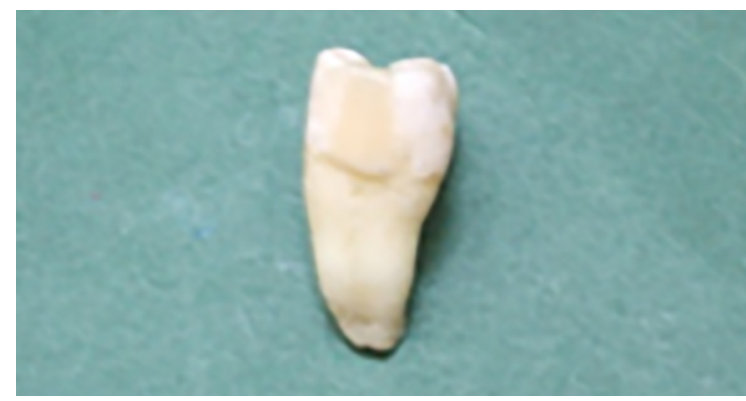

Figure 1. Sample tooth after complete restoration

Each of the three main groups was divided into three additional subgroups (9 each according to storage time.) Subgroup A: storage time was 24 hours. Subgroup B: storage time was one month. Subgroup C: storage time was three months. The specimens were stored in distilled water at $37{ }^{\circ} \mathrm{C}$ and $100 \%$ humidity in an incubator for one day, one month, and three months, respectively, according to each storage interval until microleakage testing. After completing their storage times, all of the tooth's surfaces except the restoration and 1 mm away from the cavity margins were coated with nail varnish and then by a sticky wax to ensure complete sealing of the samples. After sealing, the samples were immersed in $2.5 \%$ methylene blue dye at $37{ }^{\circ} \mathrm{C}$ for 24 hours, removed from the dye, cleaned under tap water, and then left to dry for another 24 hours. The samples were sectioned mesio-distally by using a double-sided diamond disk rotating at a low speed, and then the crown of each tooth was split longitudinally into two halves by a bi-beveled chisel. Each sample was examined microscopically by a stereomicroscope using a computerized image analyzing system. A digital image of the restoration was captured by a digital camera mounted 
on a stereomicroscope (Olympus-Model SZ-PT-Olympus Optical Co., Ltd., Japan) at 25X magnification. Image analysis software was used to measure the linear dye penetration in microns at four different points (cervical, mesioocclusal, disto-occlusal and at the center of the occlusal surface) (Figure 2). Microleakage was measured in microns by the depth of dye penetration and the results were analyzed statistically using the two-way ANOVA test.

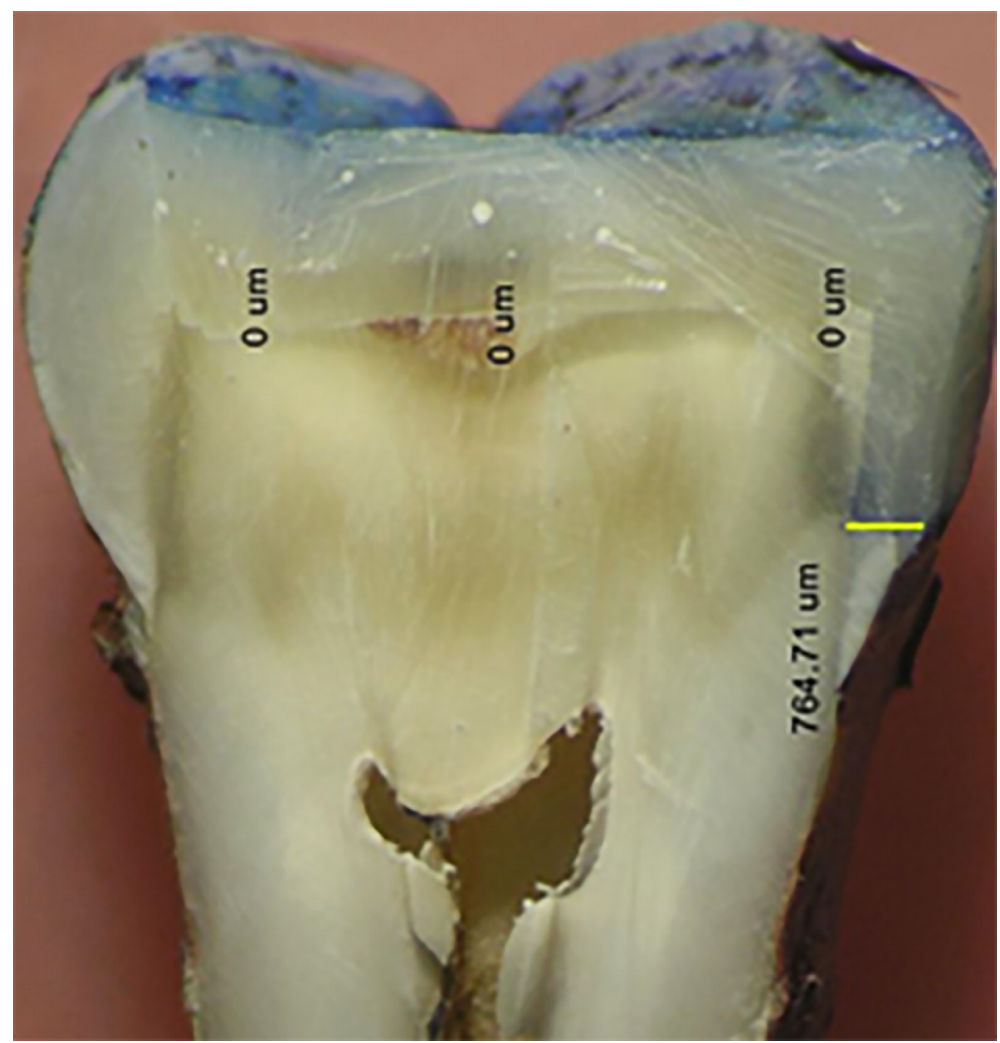

Figure 2. Level of dye penetration (measured in microns by image analysis software at four different points)

\section{Results}

Dye penetration mean \pm standard deviation values $(\mu \mathrm{m})$ at the enamel after $24 \mathrm{hr}$, one month, and three months were $1774 \pm 361.1,514 \pm 145.7$, and $973 \pm 185$, respectively (Table 1). It was observed that $24 \mathrm{hr}$ samples recorded a higher leakage rate as recorded by dye penetration, three-month samples recorded an intermediate leakage rate, while the one-month samples had a lower leakage rate, and this was highly significant statistically $(\mathrm{p}<0.01)$. Dye penetration mean \pm standard deviation values $(\mu \mathrm{m})$ at CEJ (i.e., margin placed in dentin) after $24 \mathrm{hr}$, one month, and three months were $2032 \pm 368.3,1297 \pm 389.1$, and $1691 \pm 473.5$, respectively.

Table 1. Statistical analysis of dye penetration results $(\mu \mathrm{m})$ recorded in nanohybrid groups at different locations and storage times

\begin{tabular}{|c|c|c|c|c|}
\hline \multicolumn{2}{|l|}{ Margin } & \multirow{3}{*}{$\begin{array}{l}\text { Mean } \pm \text { SD } \\
1774 \pm 361.1\end{array}$} & \multicolumn{2}{|l|}{ ANOVA } \\
\hline & & & $\mathrm{F}$ & p-value \\
\hline \multirow[t]{3}{*}{ Enamel } & 24 hour & & 19.70035 & \multirow[t]{3}{*}{$0.002308^{a}$} \\
\hline & 1 month & $514 \pm 145.7$ & & \\
\hline & 3 month & $973 \pm 185$ & & \\
\hline \multirow[t]{3}{*}{ CEJ } & 24 hour & $2032 \pm 368.3$ & 2.381746 & \multirow[t]{3}{*}{$0.173218^{\mathrm{b}}$} \\
\hline & 1 month & $1297 \pm 389.1$ & & \\
\hline & 3 months & $1691 \pm 473.5$ & & \\
\hline \multirow[t]{3}{*}{ Cementum } & 24 hour & $2138 \pm 641$ & 2.362088 & \multirow[t]{3}{*}{$0.175131^{\mathrm{b}}$} \\
\hline & 1 month & $1321 \pm 383$ & & \\
\hline & 3 months & $1901 \pm 340$ & & \\
\hline
\end{tabular}

a: Significant; b: Non-significant 
It was observed that 24-hr samples had a higher leakage rate as recorded by dye penetration; three-month samples had an intermediate leakage rate, while one-month samples had a lower leakage rate, and this was statistically nonsignificant $(\mathrm{p}>0.05)$. Dye penetration mean \pm standard deviation values $(\mu \mathrm{m})$ at the cementum after $24 \mathrm{hr}$, one month, and three months were $2138 \pm 641,1321 \pm 383$, and $1901 \pm 340$, respectively. It was observed that the 24 -hr samples had a higher leakage rate as recorded by dye penetration; the three-month samples had an intermediate leakage rate, while the one-month samples had the lowest leakage rate, and this was statistically non-significant $(\mathrm{p}>$ 0.05). It was observed that the value of dye penetration increased remarkably from enamel, CEJ to cementum, and this was statistically significant $(\mathrm{p}<0.001)$. Two-way ANOVA indicated that there was a significant difference between different locations $(p<0.001)$. Also, the storage time revealed a significant difference $(p<0.01)($ Table 2$)$.

Table 2. Two-way ANOVA test comparing dye penetration mean values $(\mu \mathrm{m})$ of hybrid groups at different locations and storage times

\begin{tabular}{|l|l|l|l|l|l|}
\hline Source of variation & $\mathrm{df}^{\mathrm{l}}$ & Sum-of-squares & Mean square & $\mathrm{F}$ & $\mathrm{p}$-value \\
\hline Margin site & 2 & 2538000 & 1269000 & 8.335 & 0.0027 \\
\hline Storage time & 2 & 3954000 & 1977000 & 12.98 & 0.0003 \\
\hline Residual & 18 & 2741000 & 152300 & & \\
\hline
\end{tabular}

1: Degree of freedom

\section{Discussion}

One of the major disadvantages of resin composite restorations is microleakage. It results from poor adhesion of the restorative material to the tooth's structure, usually at the gingival margin. When a layer of resin composite is placed in the cavity and cured, two processes occur, i.e., shrinkage of the composite and adhesion to the substrate at the same time. These two processes are opposing each other because the stresses produced by the shrinkage of the polymeric material are critical to adhesion between the resin composite and the tooth's structure. If shrinkage stresses are more than the bond strength between the resin and adhesive system, the tooth-restoration interface can break, forming a gap that results in marginal microleakage. This shrinkage of the composite depends on many factors, such as the shape and size of the cavity, the type of substrate, the location of the margins, and the type of restorative material used. It is also technique-sensitive, i.e., it depends on the technique of placement and polymerization of the composite (7). In this study, a statistically significant difference was observed in dyepenetration when the enamel margin and dentin margin (considered to be at the CEJ in this study) were compared. All dentin margins had inferior results compared to enamel margins. These variations may be explained by structural differences in the substrate. Bonding to enamel is a relatively simple process that does not have major technical requirements or difficulties. However, bonding to dentin presents a much greater challenge. Several factors account for this difference between enamel and dentin bonding. Whereas enamel is a highly mineralized tissue composed of more than $90 \%$ (by volume) hydroxyapatite, dentin contains a substantial proportion of water and organic material, primarily Type I collagen. Dentin also contains a dense network of tubules that connect the pulp with dentin-enamel junction. Dentinal tubules enclose cellular extensions from the odontoblasts and therefore are in direct communication with the pulp. The relative area occupied by dentin tubules decreases with increasing distance from the pulp. The number of tubules decreases from about 45,000 per $\mathrm{mm}^{2}$ close to the pulp to about $20,000 \mathrm{per}^{\mathrm{mm}} \mathrm{m}^{2}$ near the dentin-enamel junction (8). The tubules occupy an area of only $1 \%$ of the total surface near the dentinenamel junction, whereas they comprise $22 \%$ of the surface close to the pulp. The average tubule diameter ranges from 0.63 micrometer at the periphery to 2.37 micrometers near the pulp (9). Adhesion can be affected by the remaining dentin thickness after tooth preparation. Bond strengths are generally less in deep dentin than in superficial dentin (9). This tubular structure is not seen in enamel, which explains the difference between bonding strengths of enamel and dentin. Whenever tooth structure is prepared with a bur or other instrument, residual organic and inorganic components form a smear layer of debris on the surface (11). The smear layer fills the orifices of the dentin tubules, forming smear plugs and decreasing the permeability of the dentin by as much as $86 \%$ (12). The composition of the smear layer is basically hydroxyapatite and altered de-natured collagen. This altered collagen may even acquire a gelatinized consistency as a result of the friction and heat created by the preparation procedure (13). The fluid flow from dentinal tubules interferes with adhesion. Although the smear layer stops this fluid flow to a certain extent, submicron porosity of the smear layer still allows for diffusion of dentinal fluidonto the exposed dentin surface(14). The acidic solutions used during etching remove the smear layer and smear plugs, which may result in an increase of the fluid flow on to the prepared dentin surface. Although resin tags are formed on the dentinal tubules, the fluid may interfere with adhesion because hydrophobic resins do not adhere to hydrophilic substrates (15). Several additional factors affect dentin permeability. Besides the use of vasoconstrictor in local 
anesthesia, which decreases pulpal pressure and fluid flow in the tubules, other factors, such as the radius and length of the tubules, the viscosity of dentin fluid, the pressure gradient, the molecular size of the substances dissolved in the tubular fluid, and the rate of removal of substances by the blood vessels in the pulp, affect permeability (16). All of these variables make dentine a dynamic substrate and consequently a very difficult substrate for bonding (17).

It has been shown that when the gingival margin is placed below the cemento-enamel junction, an outer layer of cementum provides a hypo-mineralized and hyper-organic substrate for bonding. This tissue even after etching does not provide the adequate conditions for the micro-mechanical retention of an adhesive material (18). This was in agreement with the present study. In this study, least dye penetration was found at one month followed by three months' storage time. The highest dye penetration was found at one day of storage time. This may be explained by the water sorption property of composite resins. Storage of the specimens for 1 month would allow some water sorption by the resin and subsequent hygroscopic expansion of the restoration. This expansion would partly fill the marginal gap although not establishing a perfect marginal seal, but may contribute to lesser dye penetration. Conversely, 24 hours would not be enough time for hygroscopic expansion to occur (19). This was in agreement with Yap and Wang (20), who found a significant decrease in marginal gaps between one day and one week, and they found that all materials showed a decrease in gap width within one week of storage in water. This result appeared to support the results obtained by Momal and McCabe (21), who concluded that expansion caused by water sorption is able to rapidly compensate the effects of polymeric shrinkage. However, Davidson and Feilzer (22) were of the opinion that water sorption is a slow process and its compensatory effects for polymerization shrinkage often come too late. It is important to note that the amount or rate of water sorption and compensation is productspecific and may be dependent on the chemistry of the resin's matrix (23). Youngson and Jones (24) noted that marginal microleakage decreased after the second or fourth week in water storage. The results of the present study were in agreement with the results of above mentioned previous studies. These results were in agreement with the present study. Composites shrink as they polymerize, creating stresses of up to $7 \mathrm{MPa}$ within the composite mass, depending on the configuration of the preparation (2). When the composite is bonded to only one surface, such as in the case of a direct facial veneer, stresses within the composite are relieved by flow from the un-bonded surface. However, stress relief within a three-dimensional bonded restoration is limited by its configuration factor (C-factor) (26). In this study, stress relief was limited because flow can occur only from two surfaces. Unrelieved stresses in the composites may cause internal bond disruption as well as marginal gaps around the restorations that increase microleakage (27). As dentists, we should incessantly search for techniques that eliminate, or at least reduce, the microleakage to a minimum. The main limitation of this study was that it is donein vitro, while the best way to test restorative materials is in the oral cavity. Based on the results obtained from this study, future studies can be conducted to develop techniques and procedures to decrease the microleakage while bonding of resin restorations to different tooth structures.

\section{Conclusions}

Within the limitation of this study, it may be concluded that: 1) the least dye penetration was at one month of storage time, followed by three months, and one day, respectively, 2) the least microleakage was at the gingival margin located in the enamel, followed by the microleakage at CEJ, and 3) the gingival margin at the cementum had the highest microleakage.

\section{Acknowledgments:}

The authors thank the Al-Farabi College of Dentistry and Nursing (Jeddah) for its help in the study.

\section{Conflict of Interest:}

There is no conflict of interest to be declared.

\section{Authors' contributions:}

All authors contributed to this project and article equally. All authors read and approved the final manuscript.

\section{References}

1) Dalli M, Bahsi E, Sahbaz C, Ince B, Akkus Z, Ercan E et al. Atilgan A Comparison of Microleakage Scores of Five Different Types of Composite Resins. Biotechnology \& Biotechnological Equipment.2010; 24(4): 2122-26. doi: 10.2478/V10133-010-0072-9

2) Anand V.S, Kavitha C, Subbarao C. Effect of cavity design on strength of direct posterior composite restorations: An empirical and FEA analysis. Int J Dent. 2011; 214751. doi: 10.1155/2011/214751 
3) Bagheri M, Ghavamnasiri M. Effect of cavosurface margin configuration of Class V cavity preparations on microleakage of composite resin restorations. J Contemp Dent Pract. 2008; 9(2): 122-9. PMID: 18264534

4) Anusavice KJ. Philips science of dental materials. 10th ed. Philadelphia VVB. Saunders Company1996.

5) Naz F, Mahmod S, Naqi B. In vivo evaluation of microleakage of nanofilled resin composite using two different restorative techniques. Pakistan oral and dental J.2012; 32(2).

6) Opdam N, Roeters J, Kuijs R, Burqersdijk R. Necessity of bevels for box only Class II composite restorations. J Prosthet Dent.1998; 80(3): 274-9. PMID: 9760359.

7) Davidson CL, De Gee AJ, Feilzer A. The competition between the composite-dentin bond strength and the polymerization contraction stress. J Dent Res. 1984;63(12): 1396-9, PMID: 6239886.

8) Garberoglio R, Brannstrom M. Scanning electron microscopic investigation of human dentinal tubules, Arch Oral Biol.1976;21(6): 355-62. doi: 10.1016/S0003-9969(76)80003-9. PMID: 1066114.

9) Marchetti C, Piacenttini C, Menghini P. Morphometric computerized analysis on the dentinal tubules and the collagen fibers in the dentine of human permanent teeth. Bull Group Int Rech Sci Stomatol Odontol. 1992; 35(3-4): 125-9. PMID: 1297471.

10) Mitchem JC, Gronas DG. Effects of time after extraction and depth of dentin on resin dentin adhesives. J Am Dent Assoc. PMID: 3462236. 1986;113(2): 285-87.

11) Ishioka S, Caputo AA. Interaction between the dentinal smear layer and composite bond strengths. J Prosthet Dent. 1989; 61(2): 180-5. PMID: 2497241.

12) Pashley DH, Livingstone MJ, Greenhill JD. Regional resistances to fluid flow in human dentine in vitro. Arch Oral Biol. 1978; 23(9): 807-10. PMID: 299019.

13) Eick JD1, Cobb CM, Chappell RP, Spencer P, Robinson SJ. The dentinal surface: its influence on dentinal adhesion. Part I. Quintessence Int. 1991; 22(12): 967-77. PMID: 1813914

14) Pashley DH. The effects of acid etching on the pulpodentin complex. Oper Dent.1992; 17(6): 229-42. PMID: 1303516.

15) Torney D. The retentive ability of acid-etched dentin. J Prosthet Dent. 1978; 39: 169-172. doi: 10.1016/S0022-3913(78)80016-X

16) Reeder OW. Dentin permeabity determinants by hydraulic conductance. J Dent Res. 1978; 57: 187-93. doi: 10.1177/00220345780570020601. PMID: 277512

17) Soderholm KJ. Correlation of in vivo and in vitro performance of adhesive restorative materials, a report of the ASC MD156 Task Group on test methods for the adhesion of restorative materials. Dent Mater.1991; 7(2): 74-83. PMID: 1936644.

18) Cagidiaco MC, Vichi A, Ferrari M. SEM evaluation of outside dentin-cementum layer of cervical margins of class II restorations. J Dent Rest. 1996; 75: 1220

19) YAP AUJ, SHAH KC, CHEW CL. Marginal gap formation of composites in dentine: effect of water storage. J Oral Rehabil. 2003; 30(3)236-42. PMID: 12588494.

20) YAP AUJ, Wang HB, Siow KS, Gan LM. Polymerization shrinkage of visible light cured composites. Oper Dent. 2000; 25(2): 98-103. PMID: 11203806.

21) Momoi Y, McCabe JF. Hygroscopic expansion of resin based composites during 6 months of water storage. Br Dent J. 1994; 176(3): 91-6. PMID: 7599006

22) Davidson CL, Feilzer AJ. Polymerization shrinkage and polymerization shrinkage stress in polymer based restoratives. J Dent. 1997; 25(6): 435-40. PMID: 9604575.

23) AUJ, Yap KC Shahand Cl Chew. Marginal gap formation of composites in dentin, effect of water storage. Journal of Oral Rehabilitation. 2003; 30(3): 236-42. doi: 10.1046/j.1365-2842.2003.00982.x

24) Youngson CC1, Jones JC, Fox K, Smith IS, Wood DJ, Gale M. A fluid filtration and clearing technique to assesmicroleakage associated with three time bonding systems. J Dent. 1999; 27(3): 223-33. PMID: 10079629.

25) Hegdahl T, Gjerdet NR. Contraction stresses of composite filling materials. Acta Odontol Scand. 1977; 35(4): 191-95. PMID: 268922.

26) Feilzer A, De Gee AJ, Davidson CL. Setting stress in composite resin in relation to configuration of the restoration. J Dent Res. 1987; 66(11): 1636-9. PMID: 10872397.

27) Perdigao J. The interaction of adhesive systems with dentin. Am J Dent.1996; 9(4): 167-73. PMID: 9002793 